\title{
Knowledge and attitude of cardiopulmonary resuscitation training and automated external defibrillators training among medical interns in a private medical college
}

\author{
Archana Bhat ${ }^{1}$, Lulu Sherif Mahmood ${ }^{2}$, Akshatha Rao Aroor ${ }^{3}$ \\ ${ }^{1,3}$ Associate Professor, Department of Medicine, ${ }^{2} \mathrm{Head}$ of Simulation Centre, Father Muller Medical College, \\ Mangalore, Karnataka, India
}

Background: Knowledge about basic life support (BLS) is mandatory for health-care professionals. Aims and Objectives: This study is done with the objective to evaluate the knowledge about cardiopulmonary resuscitation (CPR) and use of automated external defibrillators (AEDs) among medical students who have completed MBBS course and has enrolled for internship. Materials and Methods: A cross-sectional study using a validated questionnaire was given to MBBS interns before BLS training and same questionnaire was given 1 month after the training. The questionnaire included knowledge and attitudes toward use of CPR and AED and management of choking. Results: Out of the 86 students who answered the questionnaire, the mean score was 11.28 during the pre-test. In the post-test questionnaire, the mean score was 13.91 . There was a statistically significant difference $(P=0.000)$ in the post-test scores conducted after 1 month. About $39.6 \%$ of students scored average marks (5-10) in the pre-test and $60.4 \%$ of students scored good (10-15) marks in the pre-test. After the training session in the post-test, $97.7 \%$ of students scored good marks (10-15) while only $2.32 \%$ scored average marks. $P<0.001$, Chi-square $=35.97$ is highly significant. Conclusion: BLS training helps to increase knowledge of CPR and the use of an AED.

Key words: Knowledge; Questionnaire; Basic life support study; Cardiopulmonary resuscitation

\section{Access this article online}

Website:

http://nepjol.info/index.php/AJMS DOI: 10.3126/ajms.v12i11.38699 E-ISSN: 2091-0576 P-ISSN: 2467-9100

Copyright (c) 2021 Asian Journal of Medical Sciences

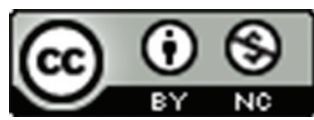

This work is licensed under a Creative Commons Attribution-NonCommercial 4.0 International License.

\section{INTRODUCTION}

Survival after cardiopulmonary arrest is usually low and depends on early intervention, quality of cardiopulmonary resuscitation (CPR), and time to defibrillation. ${ }^{1}$ It is fundamental for medical interns to receive education in basic life support (BLS).

The knowledge of BLS is a major determinant in the success of resuscitation and plays a key role in the final outcome of emergency situations. As the interns will be the future doctors, CPR training in BLS care is very crucial, this study will help us to emphasize the importance of BLS training to medical interns.
Despite many advances in medicine, sudden cardiac arrest remains a leading cause of death in most countries worldwide. ${ }^{2}$ Cardiac arrest results in the cessation of blood supply to the brain leading to the depression of breathing as well. Subsequent outcomes of cardiac arrest depend mainly on early initiation of CPR and knowledge of BLS. ${ }^{3}$ Proper practice of the techniques and maneuvers enables a person to effectively resuscitate a victim. Retention of knowledge and skills during and after training in CPR is difficult and requires systematic training with appropriate methodology.

\section{Aims and objectives}

1. The primary objective is to assess the knowledge and attitude toward CPR training and automated 
external defibrillators (AEDs) usage among medical interns

2. The secondary objective is to assess the knowledge of CPR training in BLS care for the interns in the medical college after 1 month of training.

\section{MATERIALS ANS METHODS}

A validated questionnaire with 15 questions was distributed to all the interns before the BLS training and after the BLS training after 1 month. The face and content validity of the questionnaires were done with the help of subject experts and then tested on a small sample respondent. The validity of the questionnaire was determined by piloting it on a small subgroup of BLS study aspirants in two different scenarios. The validity and reliability assessments were performed by six instructors certified in BLS. After pilot testing the questionnaire, the surveyors did modifications on the basis of suggestions that were required for better understanding. The pilot sample was not included in the final sample. The study type was prospective cohort study type with sample size 86 . The study subjects were all the interns who have passed MBBS and undergoing compulsory internship at Fr Muller Medical College. The interns who have already attended any prior resuscitation course were excluded from this study. BLS training was done as per the AHA guidelines and included both theories, practical and hands-on training. ${ }^{4}$ Pre-posttest research design was used. The post-test questionnaire was distributed 1 month later. The questionnaire included demographic details, awareness and knowledge of BLS, attitude toward BLS, and usage of AED among medical college interns and included as appendix with this article. ${ }^{5}$ McNemar tests were used to compare measurements in the pre-test and post-test results. The study was approved by Father Muller Medical College Ethics Committee.

\section{Statistical analysis}

The data collected were tabulated in MS Excel sheet and were analyzed using SPSS version 20 software. Mean and standard deviation was used for quantitative data. The pre-test and post-test questionnaire results were compared using McNemar tests. A significance level was considered at $\mathrm{P}<0.05$.

\section{RESULTS}

A total of 86 students completed the questionnaire after informed consent.

In the pre-test questionnaire, the average score by interns was 11.28 with the median score of 11 points as shown in Table 1.
In the post-test questionnaire, the average score by interns was 13.91 with the median score of 14 points.

Comparative table of responses regarding pre-test and post-test questionnaire

Analysis of the total scores of all the students between pre-test and post-test revealed $\mathrm{P}=0.000$ which is statistically significant as shown in Table 2.

Among the total 86 MBBS interns who answered the questionnaire, $47(54.6 \%)$ were female and 39 (45.4\%) were male. The correct rate of chest compression in adult BLS pre-test scenario was $81.4 \%$ which rose to $97.7 \%$ post-test after on month. The McNemar test revealed $\mathrm{P}=0.001$ which was statistically significant.

\begin{tabular}{|c|c|c|c|c|c|c|}
\hline & $\mathbf{N}$ & Mean & $\begin{array}{c}\text { Std. } \\
\text { deviation }\end{array}$ & $\begin{array}{c}\text { Change } \\
(\%)\end{array}$ & $\begin{array}{c}\text { t-test } \\
\text { P-value }\end{array}$ & \\
\hline $\begin{array}{l}\text { Pre-test } \\
\text { scores }\end{array}$ & 86 & 11.28 & 2.268 & 23.3 & 0.000 & $\mathrm{HS}$ \\
\hline $\begin{array}{l}\text { Post-test } \\
\text { scores }\end{array}$ & 86 & 13.91 & 1.316 & & & \\
\hline
\end{tabular}

\begin{tabular}{|c|c|c|c|c|c|c|}
\hline \multirow[t]{2}{*}{ Questions } & \multicolumn{2}{|c|}{$\begin{array}{l}\text { Wrong } \\
\text { answer }\end{array}$} & \multicolumn{2}{|c|}{$\begin{array}{l}\text { Correct } \\
\text { answer }\end{array}$} & \multicolumn{2}{|c|}{$\begin{array}{l}\text { McNemar } \\
\text { test P-value }\end{array}$} \\
\hline & Count & $\begin{array}{l}\text { Row } \\
\text { N \% }\end{array}$ & Count & $\begin{array}{l}\text { Row } \\
\text { N \% }\end{array}$ & & \\
\hline Pre-test q1 & 16 & 18.6 & 70 & 81.4 & 0.001 & HS \\
\hline Post-test q1 & 2 & 2.3 & 84 & 97.7 & & \\
\hline Pre-test q2 & 2 & 2.3 & 84 & 97.7 & 0.407 & NS \\
\hline Post-test q2 & 4 & 4.7 & 82 & 95.3 & & \\
\hline Pre-test q3 & 20 & 23.3 & 66 & 76.7 & 0.000 & HS \\
\hline Post-test q3 & 2 & 2.3 & 84 & 97.7 & & \\
\hline Pre-test q4 & 19 & 22.1 & 67 & 77.9 & 0.001 & HS \\
\hline Post-test q4 & 4 & 4.7 & 82 & 95.3 & & \\
\hline Pre-test q5 & 5 & 5.8 & 81 & 94.2 & 0.732 & NS \\
\hline Post-test q5 & 4 & 4.7 & 82 & 95.3 & & \\
\hline Pre-test q6 & 60 & 69.8 & 26 & 30.2 & 0.000 & HS \\
\hline Post-test q6 & 10 & 11.6 & 76 & 88.4 & & \\
\hline Pre-test q7 & 30 & 34.9 & 56 & 65.1 & 0.002 & HS \\
\hline Post-test q7 & 12 & 14.0 & 74 & 86.0 & & \\
\hline Pretest q8 & 25 & 29.1 & 61 & 70.9 & 0.000 & HS \\
\hline Post-test q8 & 6 & 7.0 & 80 & 93.0 & & \\
\hline Pre-test q9 & 17 & 19.8 & 69 & 80.2 & 0.000 & HS \\
\hline Post-test q9 & 0 & 0.0 & 86 & 100.0 & & \\
\hline Pre-test q10 & 1 & 1.2 & 85 & 98.8 & 0.317 & NS \\
\hline Post-test q10 & 0 & 0.0 & 86 & 100.0 & & \\
\hline Pre-test q11 & 3 & 3.5 & 83 & 96.5 & 0.082 & NS \\
\hline Post-test q11 & 0 & 0.0 & 86 & 100.0 & & \\
\hline Pre-test q12 & 10 & 11.6 & 76 & 88.4 & 0.001 & HS \\
\hline Post-test q12 & 0 & 0.0 & 86 & 100.0 & & \\
\hline Pre-test q13 & 45 & 52.3 & 41 & 47.7 & 0.000 & $\mathrm{HS}$ \\
\hline Post-test q13 & 12 & 14.0 & 74 & 86.0 & & \\
\hline Pre-test q14 & 45 & 52.3 & 41 & 47.7 & 0.001 & HS \\
\hline Post-test q14 & 24 & 27.9 & 62 & 72.1 & & \\
\hline Pre-test q15 & 22 & 25.6 & 64 & 74.4 & 0.136 & NS \\
\hline Post-test q15 & 14 & 16.3 & 72 & 83.7 & & \\
\hline
\end{tabular}


The question regarding site of pulse check in adult cardiac arrest victim in pre-test had correct answers in $97.7 \%$, but after 1 month was $95.3 \%$ which shows attrition in knowledge over 1 month duration. Knowledge about the correct location for chest compression in the pre-test was $76.7 \%$ and after the training was $97.7 \%$. There was statistically significant difference between pre-training and post-session 1 month $(\mathrm{P}=0.00)$.

The correct answer in chest compressions to ventilation ratio in single rescue adult BLS during pre-test was $77.9 \%$ which rose to $95.3 \%$ after the training. The McNemar test revealed statistically significant difference $(\mathrm{P}=0.001)$. AED full form was correctly answered in pre-test by $94.2 \%$ and in post-session by $95.3 \%$. There are no statistically significant changes $(\mathrm{P}=0.732)$ between pre-test and 1 month later post-test session.

Proper AED usage in the pre-test session was answered correctly by $30.2 \%$ which later increased to $84.4 \%$ in the post-test session. Knowledge about AED usage shows statistically highly significant $(\mathrm{P}=0.000)$ change after 1 month post-training session. Knowledge about AED shock in the pre-test was $65.1 \%$ and after training was $86.0 \%$. There is a statistically significant $(\mathrm{P}=0.002)$ difference between pre-training and after 1 month.

Knowledge about the use of abdominal thrusts in unconscious patient was $70.9 \%$ in the pre-test and increased to $93.0 \%$ in the post-test session. The McNemar test revealed statistically significant $(\mathrm{P}=0.000)$ change between the two values.

Knowledge about scene safety in the pre-test was $80.2 \%$ and increased to $100 \%$ in the post-test session. There is a statistically significant $(\mathrm{P}=0.000)$ difference between pretest and 1 month later post-test session. BLS full form was answered correctly in pre-test $98.8 \%$ and after training it was $100 \%$. There was no significant difference $(\mathrm{P}=0.317)$ between them.

Knowledge about correct recognition of early symptoms of stroke in the pre-test was $96.5 \%$ and was $100 \%$ in the post-test. There was no statistical significance $(\mathrm{P}=0.082)$ between pre-training and post-training sessions. Knowledge about AED usage with CPR before training was $88.4 \%$ and after the session was $100 \%$. The McNemar test reveals that there is a statistically significant difference $(\mathrm{P}=0.001)$ between the values.

Knowledge about carotid pulse in the pre-test was $47.7 \%$ which then increased to $86.0 \%$ during the post-training session. There was a statistically significant $(\mathrm{P}=0.000)$ difference between them. Knowledge about proper resuscitation sequence during the pre-test was $47.7 \%$ and increased to $72.1 \%$ after the post-training session. There was a statistically significant $(\mathrm{P}=0.001)$ between pre-test and posttest values. Management of choking scenario was correctly answered by $74.4 \%$ during the pre-test and increased to $83.7 \%$ after the training. There was no statistically significant $(\mathrm{P}=0.136)$ association in choking skills management.

The total scores were categorized as per the performance of the interns as shown in Graphs $1-3$ as poor (0-5), average (5-10), and good (10-15). In the pre-test, $34(39.6 \%)$ students scored average marks in the category (5-10) while $52(60.4 \%)$ students scored good (10-15). During the post-test, only $2(2.32 \%)$ students were in average (5-10) category whereas the rest $84(97.7 \%)$ students were in the good (10-15) category. This clearly indicates good performance in the post session.

$\mathrm{P}<0.001$, Chi-square $=35.97$ is highly significant.

The scores between pre-test and post-test were compared in Graph 4 of the critical questions asked in the questionnaire. The graph shows increase in post-test scores for most of the critical questions.

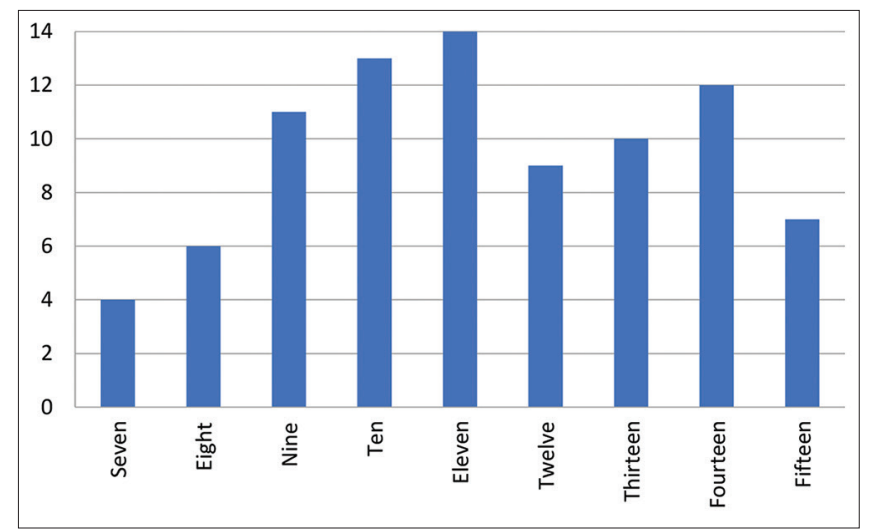

Graph 1: Pre-test scores

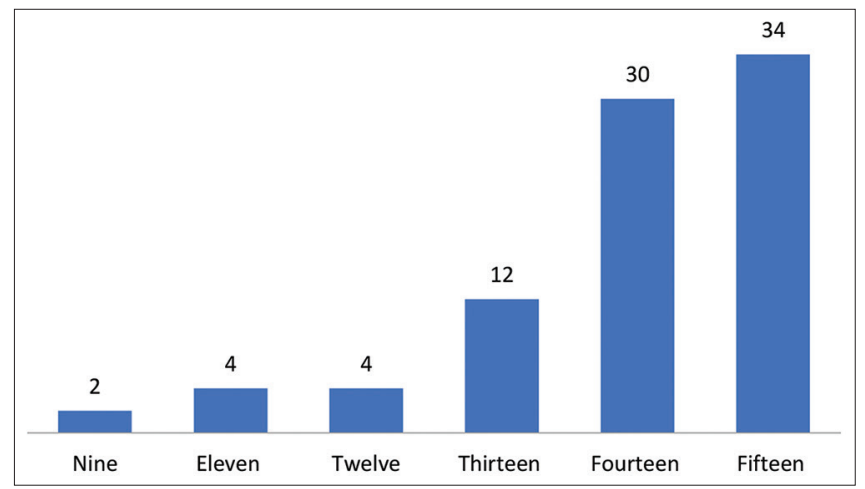

Graph 2: Post-test scores 


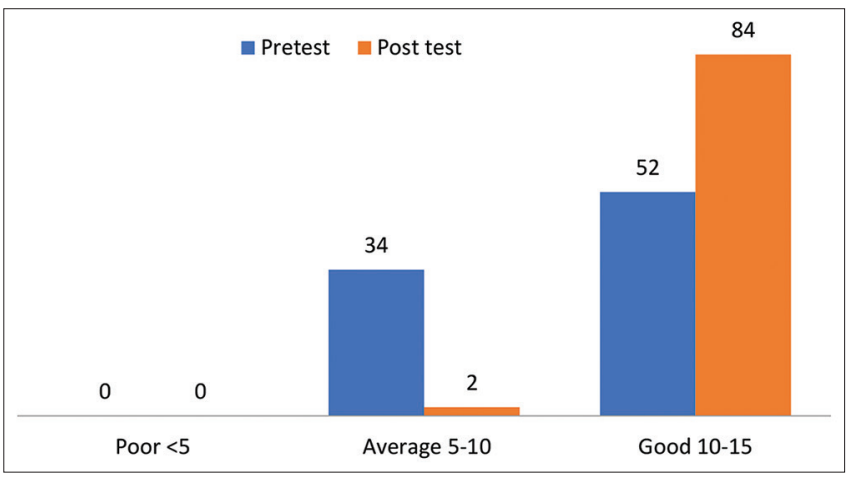

Graph 3: Grading of scores in pre-test/post-test

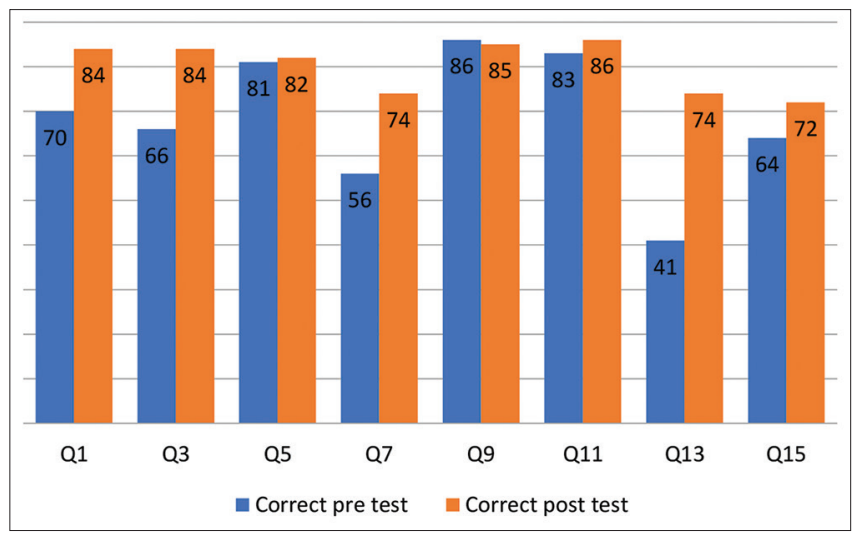

Graph 4: Analysis of scores of critical questions

\section{DISCUSSION}

This study was intended to assess the knowledge of interns about BLS, CPR, and use of AED and to reassess them after 1 week after training. Zaheer and Haque ${ }^{6}$ study showed knowledge and confidence in performing BLS increased after the structured training in BLS. Our study shows similar results with post-test scores showing statistically significant difference after the training session. In a study done by Chandan and Abraham showed regular BLS courses help to improve medical knowledge and help interns to respond to medical emergency more effectively. ${ }^{7}$ Our study also showed that after training students were well equipped to deal medical emergency scenarios like choking.

Irfan et al. ${ }^{8}$ showed that $56.0 \%$ could identify the location of chest compressions and number of chest compressions to ventilation was $49.0 \%$. Retention of knowledge of BLS course is difficult with time and can be improved by periodical reinforcement.

\section{Limitations of the study}

The study assesses the knowledge about BLS and retention of the knowledge after 1 month of training and not the performance skills.

\section{CONCLUSION}

Educational training in BLS will increase CPR performance and AED usage among the interns. BLS awareness among interns can be increased by certified training programs.

\section{ACKNOWLEDGMENTS}

We thank all the students who participated in this study. We would like to thank Simulation Centre, Father Muller Medical College for the contribution to the data collection and the study.

\section{REFERENCES}

1. Kallestedt $\mathrm{ML}$, Berglund $\mathrm{A}$, Herlitz $\mathrm{J}$, Lepppert $\mathrm{J}$ and Enlund $\mathrm{M}$. The impact of CPR and AED training on healthcare professionals self percieved attitudes to performing resuscitation. Scand $\mathrm{J}$ Trauma Resusc Emerg Med. 2012;20:26.

https://doi.org/10.1186/1757-7241-20-26

2. Gebremedhn EG, Gebregergs GB and Anderson BB. The knowledge level of final year undergraduate health science students and medical interns about cardiopulmonary resuscitation at a university teaching hospital of Northwest Ethopia. World J Emerg Med. 2014;5(1):29-34. https://doi.org/10.5847/wjem.j.issn.1920-8642.2014.01.005

3. Al Mohaissen MA. Knowledge and attitudes towards basic life support among health students at a Saudi women's university. Sultan Qaboos Univ Med J. 2017;7(1):151-156. https://doi.org/10.18295/squmj.2016.17.01.011

4. ECC Committee, Subcommittees and Task Forces of the American Heart Association. 2005 American Heart Association Guidelines for cardiopulmonary resuscitation and emergency cardiovascular care. Circulation. 2005;112(24 Suppl):IV1-203. https://doi.org/10.1161/circ.112.24_supplement.b2

5. Pande S, Pande S, Parate V, Pande S and Sukhsohale N. Evaluation of retention of knowledge and skills imparted to firstyear medical students through basic life support training. Adv Physiol Educ. 2014;38(1):42-45.

https://doi.org/10.1152/advan.00102.2013

6. Zaheer $\mathrm{H}$ and Haque $\mathrm{Z}$. Awareness about BLS (CPR) among medical students: Status and requirements. J Pak Med Assoc. 2009;5(1):57-59.

7. Chandran KV and Abraham SV. Basic life support: Need of the hour a study on the knowledge of basic life support among young doctors in India. Indian J Crit Care Med. 2020;24(5):332335.

https://doi.org/10.5005/jp-journals-10071-23442

8. Irfan B, Zahid I, Khan MS, Aziz Khan OA, Zaidi S, Awan S, et al. Current state of knowledge of basic life support in health professionals of the largest city in Pakistan: A cross sectional study. BMC Health Serv Res. 2019;19:865.

https://doi.org/10.1186/s12913-019-4676-y

9. Chamberlain D, Smith A, Woollard M, Colquhoun M, Handley AJ, Leaves $\mathrm{S}$, et al. Trials of teaching methods in basic life support (3): Comparison of simulated CPR performance after first training and at 6 months. Rescucitation. 2002;53(2):179-187. https://doi.org/10.1016/s0300-9572(02)00025-4 


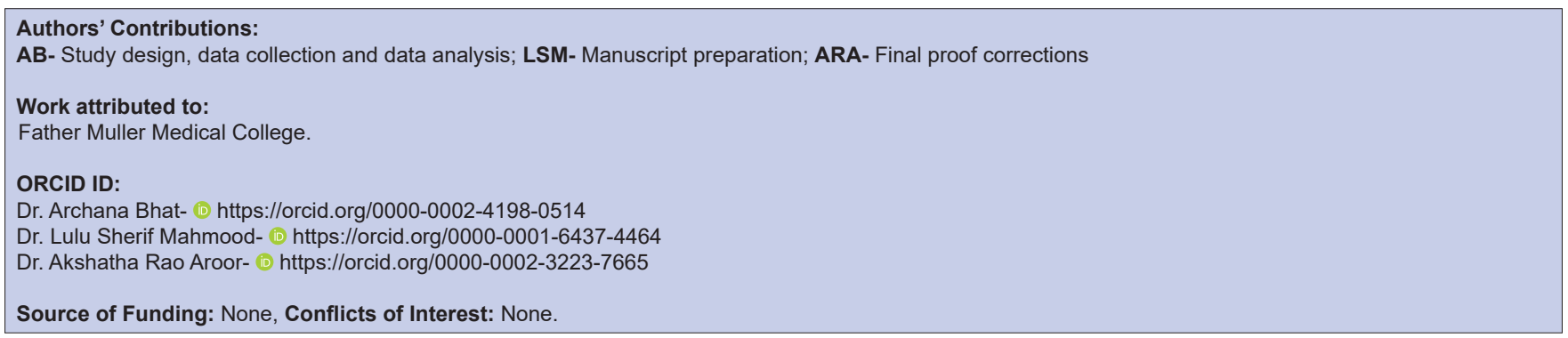

\section{APPENDIX}

The same questionnaire used for pre-test and posttest is given below

1. Rate of chest compressions for an adult CPR?

- $120-150 / \mathrm{min}$

- $100-120 / \mathrm{min}$

- $70-100 / \mathrm{min}$

- $80-100 / \mathrm{min}$

2. Pulse is assessed in an adult cardiac arrest victim at

- Femoral pulse

- Carotid pulse

- Radial pulse

- Brachial pulse

3. What is the location for chest compression?

- Upper end of the sternum

- Lower end of the sternum

- Middle of the sternum

- Left side of the sternum

4. In adults, the chest compressions and ventilation ratio for single rescue in adult BLS

- $30: 2$

- 15:2

- $30: 1$

- $15: 1$

5. What does AED stand for?

- AED

- Automatic extra debriefer

- Automatic external defibrillator

- Automated extra debriefer

6. The proper and first step for operating AED is

- Placing the pads

- Switch on the pads

- Applying the shock

- Analyze the rhythm
7. After the AED has delivered the shock you should

- Resume compressions

- Restart to check pulse

- Analyze the H and T of cardiac arrest

- Switch roles

8. Use of abdominal thrusts to relieve choking in an unconscious patient

- True

- False

9. When you find someone unresponsive in the middle of the road what will your first response be?

- Verify scene is safe

- Scream for help

- Call for doctor

- Check for carotid pulse

10. What does BLS stand for?

- BLS

- Basic light support

- Basic life standard

- Between life support

11. You have been talking with a 60 -year-old man. He is alert and has been conversing normally. All at once he complains of sudden weakness on one side of his face and in one arm and has trouble while speaking. What is the most likely problem?

- A seizure

- A heart attack

- A stroke

- Diabetic come

12. An AED should be used

- Before performing cpr

- After performing cpr 
13. How long should you check for a carotid pulse on an adult?

- For at least $30 \mathrm{~s}$

- For at least a full minute

- $10-15 \mathrm{~s}$

- $5-10 \mathrm{~s}$

14. You just performed 5 cycles of CPR on an adult. You reassess the pulse. No pulse is present. What is your next course of action?

- Search for an AED

- Call for help
- Continue CPR

- None of the above

15. A 50-year-old man who has been eating steak in restaurant abruptly stands up and grabs his neck. The rescuer determines that the victim is choking. The best response is to

- Use back blows

- Do nothing wait until the victim becomes unresponsive, then start CPR

- Use abdominal thrusts

- Use upward chest thrusts 